\title{
The Impact of Job Satisfaction on Employees' Performance: A Case Study of Al Hayat Company - Pepsi Employees in Erbil, Kurdistan Region - Iraq
}

\author{
Sabir Sadiq Abdulkhaliq ${ }^{1}$ \\ Zrar Mohsin Mohammadali
}

\begin{abstract}
The main purpose of this study was to investigate the effect of job satisfaction on employees' performance: Case study of Al Hayat Company - PEPSI employees in Erbil, Kurdistan Region - Iraq. The method of this research is descriptive-survey, in terms of nature, it is applied and also in terms of time it is cross-sectional. The statistical population of this study consisted of most employees of this company in Erbil, with a sample size of 173. The sampling method was simple random. Data were collected using two standard questionnaires for job satisfaction and employee performance, which were confirmed by Cronbach's alpha coefficient and composite reliability coefficient of the questionnaires. The validity of the questionnaire was confirmed by convergent validity (confirmation of factor loadings and AVE value) and discriminate validity. Descriptive statistics and confirmatory factor analysis were used to analyze the data, and structural equation modeling technique in PLS software was used to investigate the model before testing the hypotheses, the outer model of the research, the internal model and the model overall were fitted with the appropriate indices. Finally, the results showed that job satisfaction has a positive and significant effect on the performance of employees of Al Hayat Company - PEPSI in Erbil. The results of the study indicate that managers need to focus more on their employees. In fact, employees are the most costly to the organization, but can contribute to the growth and profitability of the company in terms of performance.
\end{abstract}

KEYWORDS: Job Satisfaction, Employee Performance, Al Hayat Company - PEPSI

JEL CLASSIFICATION: $M 1, M 12$

\section{INTRODUCTION}

Human resources are considered as the most important and valuable resources in the success of the organization because the human resources of the organization are capable of changing their performance and are the main means of achieving organizational goals. Therefore, attention is given to organizational managers by the mental and physical needs of employees and they try to improve the personal and occupational performance of employees in different forms and ways such as training, performance evaluation, and job design. The success and failure of an organization depends on the job performance of its employees. Dugguh and Dennis (2014) state that performance is an evidence of individual success and employee performance is a multi-dimensional structure. Job performance is the degree of fulfillment of one's duties of the job. Mueller and Kim (2008) recognized two types of job satisfaction;

\footnotetext{
${ }^{1}$ Soran University, Iraq, sabir.abdulkhaliq@ soran.edu.iq

2Erbil Polytechnic University - Iraq, Iraq, zrar.mohammed@epu.edu.iq
} 
firstly, the general feeling about the job, and secondly, the feelings about the characteristics of the job, such as benefits, position, salary, job atmosphere, growth opportunities, and the relationships between employees. Increasing the efficiency and productivity of any organization requires the optimal use of all the factors that influence the production or delivery of services. Since human resource is an important factor in any organization, organizational productivity and efficiency also depend on the performance of its employees (Prange \& Pinho, 2017).

Job satisfaction is an employee's mental perspective that includes the way that they feel about their job and the employers' organization. In addition, job satisfaction is an enjoyable emotional state that results from achieving job values (Courtney \& Yonkong, 2017). As known that every organization or institution is made up of three major human, physical and financial resources, but it is certainly the most important human resource of any organization ${ }^{1}$ to achieve the goals and development of the organization, because the other two sources, even if they are in very high quality, they are tools that are in the hands of human resources which must be used to achieve their goals. In any organization, everybody expects a large part of their material and psychological needs to be met after choosing a job, but if for some reason, such as inadequate planning and management fails to address their physical and psychological needs, not only can feel satisfied with his/her work, but also with an undesirable mood in the organization, negatively affecting his/her mental health (Lin et al., 2014).

\section{JOB SATISFACTION}

Job satisfaction is a significant aspect of success in any organization (Amburgey, 2005). Job satisfaction reflects the relative feelings, objective thoughts, and behavioral intentions of employees in an organization that help predict employee behavior (Brown et al., 2013). Therefore, Job satisfaction can be used as part of evaluations that lead to planning for organizational improvement by presenting results from past strategies and future projections of employees. Pleased and motivated employees will guarantee the organization's long term success and it is believed that job satisfaction by all employees in any organization is directly related to their level of motivation (Hee et al., 2019). Research shows that employees with higher levels of job satisfaction are physically and mentally fit, but those who are dissatisfied with their job are often disappointed and pessimistic. Job satisfaction is one of the most important variables in the field of organizational behavior because each organization has specific goals that constitute the existential philosophy of that organization. Gupta and Garg (2017) in their research expressed that employees are dissatisfied with their supervisor's behaviour such as, paying salary, internal policies, promotional opportunities and organizational management. One of the most important consequences of job dissatisfaction is the quantitative and the qualitative decline in performance. Naturally, this can lead to long absences, irregularities in entry and exit, underemployment and inaccuracies and will have a negative impact on performance. This means that people who suffer from severe job stress due to job dissatisfaction cannot be expected to perform well as a happy person and away from stress. Obviously, job satisfaction or dissatisfaction is only one of the factors affecting employees' performance, so in order to improve the performance of employees, more research is needed to identify the factors that influence employees' good performance and to find ways to overcome the obstacles, and ultimately increase the efficiency and effectiveness of organizations (Fu \& Deshpande, 2014).Certainly, skilled and efficient workforce is one of the most important tools to achieve the goals of the organization and plays an important role in 
increasing the efficiency of the organization. In recent years, much attention has been paid to the relationship between employee mood characteristics and organizational outcomes. Understanding social attitudes and behavior is essential to move society toward transcendent social values (Platis et al., 2015) these include job satisfaction, work, and the individual's relationship with the organization and employee performance. Singhai (2016) believes that job satisfaction as the assessment of the employee's job and his/her company as contributing rightfully to the achievement of one's individual purpose. The substantial time spent by employees at the workplace makes job satisfaction an important factor as dissatisfaction can have an unfavorable impact on the employee's personal life as well (Abuhashesh et al., 2019). The general attitude of people towards their job is a behavioral phenomenon that is interpreted as job satisfaction and is the result of one's positive and negative beliefs about the dimensions of his or her job. Job satisfaction can be considered a psychological factor and it is considered a kind of emotional adjustment to the job and the conditions of employment. That is, if the job in question gives the person pleasure, then the person is satisfied with the job. Conversely, if the desired job does not provide the desired satisfaction and enjoyment tomorrow, then the person begins to blame the job and seeks to change it (Shooshtarian et al., 2013). A review of the theories of personal psychology and human resource management experts on job satisfaction shows that job satisfaction is a multidimensional concept and is related to several factors. In other words, job satisfaction will be achieved through the realization of a set of factors, including the nature and conditions of work, salary, opportunities for career advancement, how to supervise, relationships with colleagues, and so on. Of course, job satisfaction is also somewhat dependent on genetic factors and individual characteristics (Bakotić, 2016). In the meantime, Herzberg's two-factor theory (motivation-health) is one of the most comprehensive motivational theories that divides motivational factors into motivational and health categories. In his view, health factors lead to dissatisfaction in individuals, and motivational factors increase their motivation to work. Overall, job satisfaction is one of the most challenging organizational concepts and the basis of many management strategies to increase organizational productivity and efficiency (Arifin, 2015). Studying job satisfaction has two important aspects: First, it is a human aspect that deserves to be treated fairly and respectfully by employees. And second, the behavioral dimension that attention to job satisfaction can guide employees' behavior in a way that affects their organizational performance and duties and their performance. Therefore, the purpose of this study was to investigate the impact of job satisfaction on the performance of Al Hayat Company - PEPSI staff in Erbil, Iraqi Kurdistan.

\section{EMPLOYEE PERFORMANCE}

The performance consists of the results of actions taken by employees based on their skills and expertise. Shields et al., (2015) define employee performance as the degree to which employees perform their duties and responsibilities. Dugguh and Dennis (2014) consider that performance is a behavior and it is one of the most important factors in the success of the organization (Dahkoul, 2018). As a result, employee performance is an activity that is related to the job predictable to an employee and how the activity is accomplished (Sari et al., 2019). Learning organizations also play a significant role in improving employee performance by providing training and enhancements to their employees.

Various researches have been conducted on this subject which have had different results. (Platis et al., 2015) showed that there is a positive and significant relationship between job satisfaction and job performance of employees. Moreover, principal component analysis showed that factors such as: Managers satisfaction, Satisfaction with working methods, 
Satisfaction with cognition, Working time satisfaction and job security were more important. The results of Bakotic (2016) showed that there is a direct relationship between employee job satisfaction and organizational performance in both directions, but the intensity of the relationship is very weak. Also, Kampkötter (2017) found that financial rewards have a significant effect on employee performance. (Yuen et al., 2018) also showed that job satisfaction was significantly related to job performance. In addition, the amount of workrelated stress and reward attractiveness are key determinants of job satisfaction. Torlak and Kuzey (2019) found that inspirational management, intellectual stimulation, and personal attention were positively associated with job satisfaction and job performance. Whereas, the possible rewards related to job satisfaction and job performance had no significant effect.

While the employees are satisfied with their job, they are expected to take pleasure in the experience which they have received and they get less level of stress (Bakotic, 2016). In addition, satisfied employees normally have a positive viewpoint concerning their environment. This positive outlook in the organization or company is responsible for improving the performance of employees and the organization in general (Khalaf et al., 2019). When employees are willing to take their responsibilities for solving the organizational problems, the employees' performance and the whole organization could be improved. Here it is imperative to point out that the relationship between job satisfaction and organizational performance is complex; the research on it is rare; and theoretical and practical studies have not yielded an unambiguous answer to the real nature and strength of the connection between job satisfaction and organizational performance. In fact, some authors have found a positive correlation between job satisfaction, organisational and employee performance (Abuhashesh et al., 2019; Bakotić, 2016; Chan, et al., 2000; Ellingeret al., 2002; Huselid, 1995; Koys, 2001; Miha, 2018;Shaju\&Subhashini, 2017) whilst, some of these studies have not discovered any statistically significant correlation between these two variables (Daily \&Near, 2000; Mohr \&Puck, 2007).On the other hand, after the operation Iraq freedom in 2003, Kurdistan of Iraq is witnessing the economic prosperity and development of more reputable international companies and brands, so there are a lot of employees working in these companies which paying attention to their satisfaction can probably improve the performance of the company. Al-Hayat - PEPSI Company, founded in 2004 and specializes in the bottling and distribution of beverages and mineral water. The company owns the exclusive PESPSICO INTERNATIONAL (PCI) franchise in Kurdistan region of Iraq. In order to attract customers, the company's first goal is to promote products. It therefore utilizes various marketing tactics to achieve this goal as well as the company's advertising techniques have long been popular with the public. The most important strategies of these companies are: advertising, direct marketing, employing high PR, engaging with the customer and promoting the sales.

Therefore, as it is clear that employees play an important role in the company's sales strategies, based on the results of previous research, this article seeks to focus on the relationship between job satisfaction and employee performance in Al Hayat Company PEPSI Erbil, Kurdistan region of Iraq.

\section{RESEARCH METHODOLOGY}

This research is an applied research in terms of purpose as well as descriptive-correlation in terms of data collection, and finally, in terms of time horizon, it is a cross-sectional study. The population of the study is most of the Al Hayat Company - PEPSI in Erbil, 173 of whom were selected by simple random sampling. A standard questionnaire was used to measure each of the research variables. Paterson 1992 questionnaire was used to measure job performance. The questionnaire included 15 descriptive items, but three additional items were added to this 
study. The questionnaire is rated using a 5-point Likert scale. A 19-item Minnesota Questionnaire (MSQ) that measures job satisfaction in six dimensions was used to measure job satisfaction and one question was omitted. These six dimensions include, payment system (questions 1,2,3), type of job (questions 4,5,6,7), opportunities for improvement (questions $8,9,10$ ), organizational climate (questions 11,12), Leadership style (Questions 13,14,15) physical condition (Questions 16,17,18) rated on a five-point Likert scale. The validity and reliability of this questionnaire have been confirmed by experts. The reliability of the research questionnaire was confirmed by using Cronbach's alpha coefficients and composite reliability as well as validity using convergent validity (factor loadings and AVE values) and diacritical validity. Cronbach's alpha coefficients and composite reliability coefficients should be greater than 0.7 and all factor loadings and AVE values greater than 0.5 . The results of each indicator are presented in the table 1 and 2.

Table 1. Composite reliability coefficient, Cronbach's alpha and AVE value

\begin{tabular}{|c|c|c|c|}
\cline { 2 - 4 } \multicolumn{1}{c|}{} & Cronbach's Alpha & $\begin{array}{c}\text { Composite } \\
\text { Reliability }\end{array}$ & $\begin{array}{c}\text { Average Variance } \\
\text { Extracted (AVE) }\end{array}$ \\
\hline Job Type & 0.872 & 0.709 & 0.502 \\
\hline Job performance & 0.864 & 0.887 & 0.501 \\
\hline Opportunities improvement & 0.706 & 0.835 & 0.628 \\
\hline Organizational climate & 0.712 & 0.814 & 0.688 \\
\hline Payment system & 0.787 & 0.867 & 0.687 \\
\hline Physical conditions & 0.746 & 0.750 & 0.503 \\
\hline Leadership style & 0.735 & 0.850 & 0.655 \\
\hline
\end{tabular}

Source: author's calculation

Table 2.Discriminant validityresults

\begin{tabular}{|c|c|c|c|c|c|c|c|}
\hline & 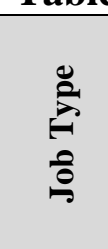 & 을 & 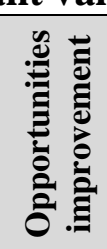 & 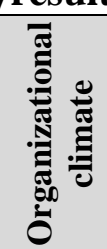 & 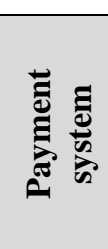 & 预 & 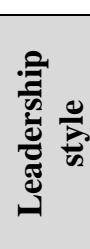 \\
\hline Job Type & 0.820 & & & & & & \\
\hline Job performance & 0.533 & 0.779 & & & & & \\
\hline Opportunities improvement & 0.554 & 0.590 & 0.792 & & & & \\
\hline Organizational climate & 0.321 & 0.236 & 0.387 & 0.829 & & & \\
\hline Payment system & 0.494 & 0.312 & 0.309 & 0.340 & 0.829 & & \\
\hline Physical conditions & 0.322 & 0.545 & 0.273 & 0.302 & 0.274 & 0.709 & \\
\hline
\end{tabular}

As shown in the tables (1) and (2), all values are higher than the specified value, so the reliability and validity of the questionnaire were confirmed.

\subsection{Research Questions}

The study required to examine the following research questions to achieve the study objectives:

1. Is there an impact of job satisfaction on employees' performance?

2. Which of the dimensions of job satisfaction has the most impact on employees' performance? 


\subsection{Research Objectives}

It is evident in the literature that there is a relationship between job satisfaction and employee performance. Nevertheless, this study aimed to evaluate the validity of this relationship from the workplace of Al Hayat Company - PEPSI in Erbil. As a result, the objectives of this study are:

1. To find out whether there is a positive relationship between job satisfaction and employee performance.

2. To determine which of the dimensions of job satisfaction such as payment system, type of work, improvement opportunities, organizational climate, leadership style, and physical condition will lead to better employee performance.

\section{RESULTS AND FINDINGS}

The results of the descriptive findings showed that by age $85 \%$ were male and $15 \%$ female, and the gender of one person was unknown. Also by age 11 people under 20, 40 people 20-25, 46 people 26-30 years, 39 people $31-35$ years, 30 people $36-40$ years, 5 people $41-45$ years old and only two people above it's been 45 years. In terms of education, 14 people were illiterate, 12 people were elementary, 17 people were secondary, 16 people were high school, 38 people were high school diplomas, 69 people were bachelors and 7 people were masters. In terms of marital status, 55 people were single, 117 people were married, and one was unknown. Based on the duration in service of employees; 34 people were under 1 year, 75 people were 1-3, 49 people were 4-6, and 15 people over 6 years.

The Pearson correlation coefficient test was used to examine the relationship between job satisfaction and job performance. Results showed that the relationship between paying system and job performance was 0.468 (sig $=0.001)$, opportunities for improvement with job performance 0.385 ( $\mathrm{sig}=0.001)$, Job type with job performance $0.38(\mathrm{sig}=0.001)$, organizational climate with job performance $0.395(\mathrm{sig}=0.001)$, physical condition with job performance $0.231(\mathrm{sig}=0.002)$.

Therefore, it can be said that all dimensions of job satisfaction have a positive and significant relationship with job performance of employee. Also, the relationship between job satisfaction and job performance is 0.569 which is significant at 0.05 level of error because the level of significance is 0.001 .

Table 3. Pearson correlation coefficient test results

\begin{tabular}{|c|c|c|}
\hline \multicolumn{3}{|c|}{ Correlations } \\
\hline \multicolumn{3}{|c|}{} \\
\hline \multirow{3}{*}{ Paymentsystem } & Pearson Correlation & Performance \\
\cline { 2 - 3 } & Sig. (2-tailed) & .468 \\
\cline { 2 - 3 } & $\mathrm{N}$ & .000 \\
\hline \multirow{3}{*}{ JobType } & Pearson Correlation & 173 \\
\cline { 2 - 3 } & Sig. (2-tailed) & .380 \\
\cline { 2 - 3 } & $\mathrm{N}$ & .000 \\
\hline \multirow{3}{*}{ Opportunitiesimprovement } & Pearson Correlation & 173 \\
\cline { 2 - 3 } & Sig. (2-tailed) & .385 \\
\cline { 2 - 3 } & $\mathrm{N}$ & .000 \\
\hline
\end{tabular}




\begin{tabular}{|c|c|c|}
\hline \multicolumn{3}{|c|}{ Correlations } \\
\hline & & Performance \\
\hline \multirow{3}{*}{ Organizationalclimate } & Pearson Correlation & .395 \\
\hline & Sig. (2-tailed) & .000 \\
\hline & $\mathrm{N}$ & 173 \\
\hline \multirow{3}{*}{ Leadershipstyle } & Pearson Correlation & .406 \\
\hline & Sig. (2-tailed) & .000 \\
\hline & $\mathrm{N}$ & 173 \\
\hline \multirow{3}{*}{ Physicalconditions } & Pearson Correlation & .231 \\
\hline & Sig. (2-tailed) & .002 \\
\hline & $\mathrm{N}$ & 173 \\
\hline \multirow{3}{*}{ JobSatisfaction } & Pearson Correlation & .569 \\
\hline & Sig. (2-tailed) & .000 \\
\hline & $\mathrm{N}$ & 173 \\
\hline
\end{tabular}

Source: author's calculation

In order to investigate the effect of job satisfaction dimensions on job performance, structural equation modeling is used in PLS software. First, the model is shown in two standard coefficients and significant coefficients (figure 1), and then the fit of the proposed model is investigated.

Model fit is investigated in three modes. In the first case the outer model of the research is examined (this is the same as the reliability and validity of the questionnaire that was investigated), in the second case the internal model of the research includes path coefficients, coefficient of determination R2, The effect size of F2 Q2 has been considered. Initially for the coefficient of determination, although the researchers considered values as $0.19,0.33$, and 0.67 , respectively, as weak, medium, and strong, the optimal value depends on the subject of the research and the number of its latent variables. The results show that the values of the coefficient of determination are much higher than the standard values. 


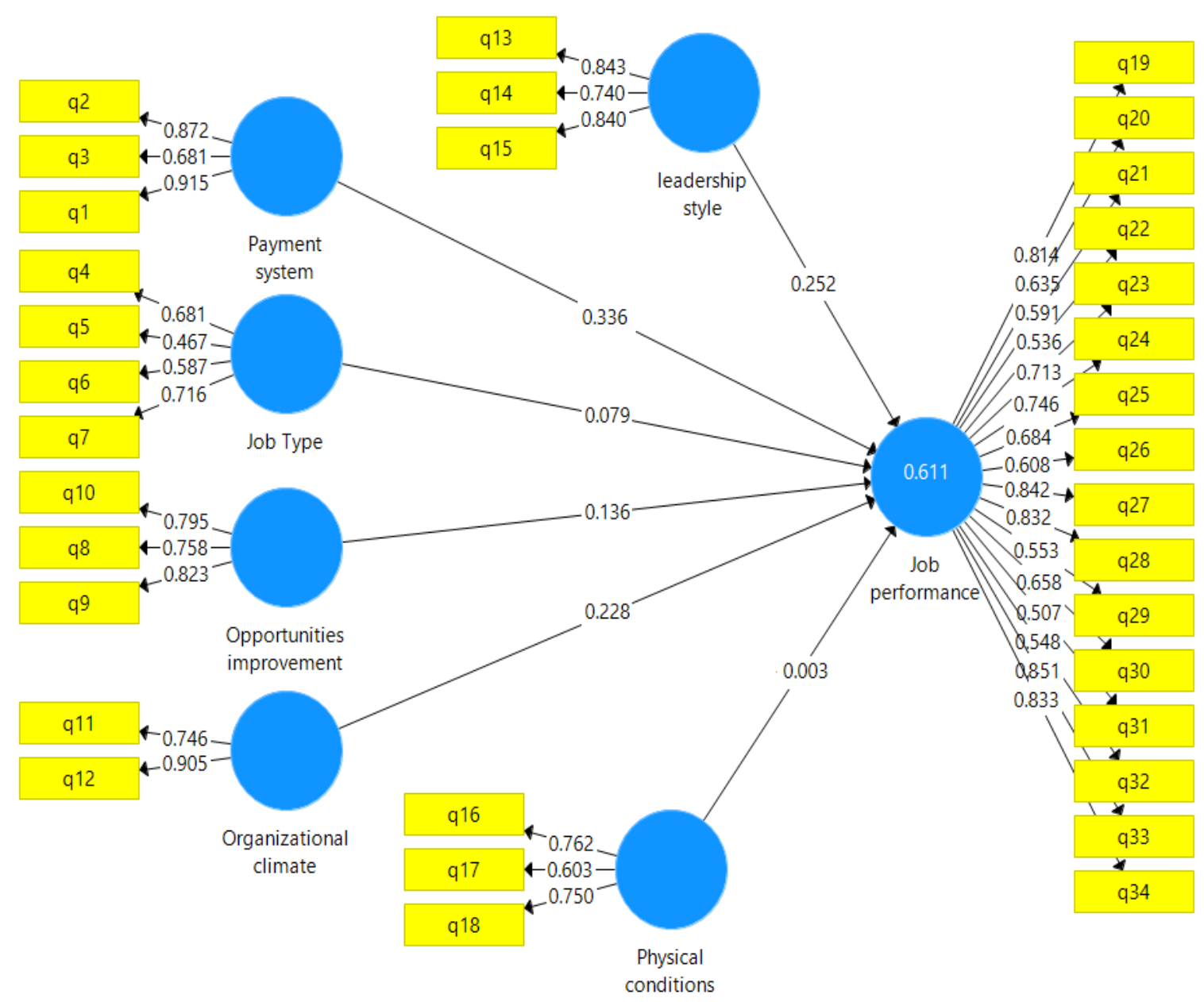

Figure 1. Model in standard mode

The effect size, or F2, means the explanatory power of the model and determines the relationship between model structures, and respectively, the values of $0.02,0.15$ and 0.35 indicate the magnitude of small, medium and large impacts of one structure to another. 


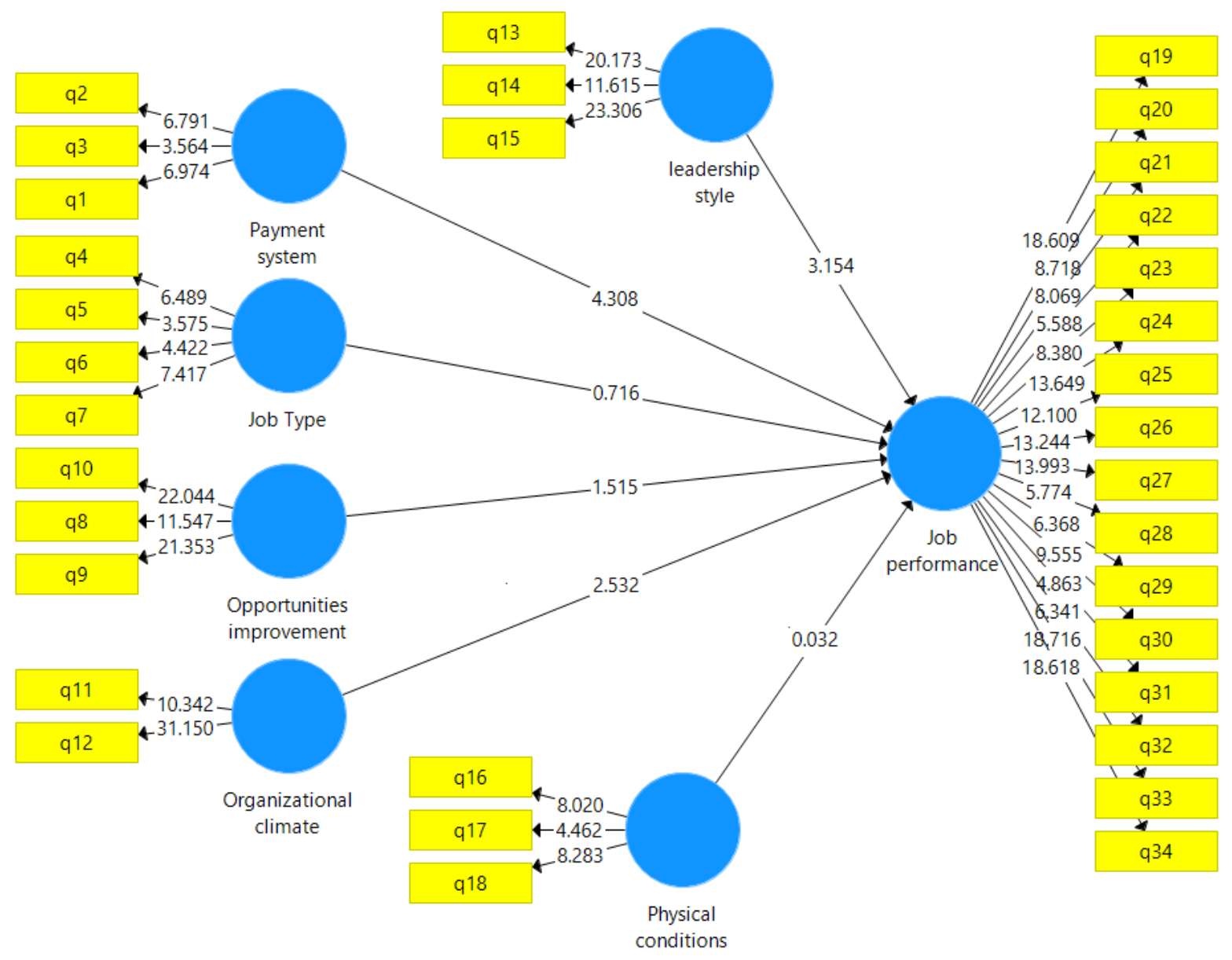

Figure 2. Model in the state of significant coefficients

Table 4. Results R2

\begin{tabular}{|l|l|l|}
\cline { 2 - 3 } \multicolumn{1}{c|}{} & R Square & R Square Adjusted \\
\hline Job performance & 0.611 & 0.586 \\
\hline
\end{tabular}

Table 5. Results F2

\begin{tabular}{|l|l|}
\cline { 2 - 2 } \multicolumn{1}{l|}{} & Job performance \\
\hline Job Type & 0.023 \\
\hline Opportunities improvement & 0.073 \\
\hline Organizational climate & 0.167 \\
\hline Payment system & 0.267 \\
\hline Physical conditions & 0.120 \\
\hline Leadership style & 0.187 \\
\hline
\end{tabular}

To fit the overall model, three indices, including RMS Theta, NFI and SRMR (Mean Difference between Data) were used Table 6). The SRMR index also determines to what extent the conceptual model is consistent with empirical data. The value is 0.08 red line. In this study, the SRMR index is about 0.070, which is considered to be a good value. That is, the overall model is well-fitted. 
Also, the RMS Theta index is the effective value of the residual covariance matrix from the residuals of the outer model and assumes a value of less than 0.12 for the model utility. In this study, this index is 0.177 . Also, the NFI index should be higher than 0.9 , which is 0.908 in the calculations, which is a good value.

As shown in the table 6 all the values obtained for the fit indices are acceptable. Accordingly, the fit of the model overall was confirmed.

Table 6. Model fit indices

\begin{tabular}{|c|c|l|}
\hline Fit indices & The value obtained & Optimal \\
\hline SRMR & 0.07 & Less than 0.08 \\
\hline RMS THETA & 0.117 & Less than 0.12 \\
\hline NFI & 0.908 & Greater than 0.9 \\
\hline
\end{tabular}

Finally, the results of the simultaneous effect of all 6 dimensions of job satisfaction on the job performance of Al Hayat Company - PEPSI Employees in Erbil, showed that the payment system dimension with an impact factor of 0.336 , the leadership style dimension with an impact factor of 0.252 and the organizational climate dimension with an impact factor of 0.228 had a significant effect on employees' performance.

It should be noted that with regard to the coefficient of determination, it can be said that these 6 dimensions were able to explain $61 \%$ of the changes in job performance of employee (Table 7).

Table 7. Results related to the impact of job satisfaction dimensions on job performance

\begin{tabular}{|c|c|c|c|c|}
\cline { 2 - 5 } \multicolumn{1}{c|}{} & $\begin{array}{c}\text { Original } \\
\text { Sample (O) }\end{array}$ & $\begin{array}{c}\text { Standard Deviation } \\
\text { (STDEV) }\end{array}$ & $\begin{array}{c}\text { T Statistics } \\
(\mid \mathbf{O} / \text { STDEV|) }\end{array}$ & $\begin{array}{c}\text { P } \\
\text { Values }\end{array}$ \\
\hline Job Type -> Job performance & 0.079 & 0.110 & 0.716 & 0.474 \\
\hline $\begin{array}{c}\text { Opportunities improvement -> } \\
\text { performance }\end{array}$ & 0.136 & 0.090 & 1.515 & 0.130 \\
\hline $\begin{array}{c}\text { Organizational climate -> } \\
\text { Jobperformance }\end{array}$ & 0.228 & 0.090 & 2.532 & 0.012 \\
\hline $\begin{array}{c}\text { Payment system -> Job } \\
\text { performance }\end{array}$ & 0.336 & 0.078 & 4.308 & 0.000 \\
\hline $\begin{array}{c}\text { Physical conditions -> Job } \\
\text { performance }\end{array}$ & 0.003 & 0.087 & 0.032 & 0.974 \\
\hline $\begin{array}{c}\text { Leadership style -> Job } \\
\text { performance }\end{array}$ & 0.252 & 0.080 & 3.154 & 0.002 \\
\hline
\end{tabular}




\section{DISCUSSION AND CONCLUSION}

This study examined the impact of job satisfaction on the performance of Al Hayat Company - PEPSI Employees in Erbil, Kurdistan Region - Iraq. The results showed that there is a positive and significant relationship between job satisfaction and employees' performance. There is also a positive and significant relationship between the dimensions of job satisfaction and payment system, type of job, opportunities for promotion, organizational climate, leadership style and physical condition and staff performance. This means that increased job satisfaction leads to improved employee performance. The results of this study are in line with the results of (Bakotić, 2016; Kampkötter,2017; Platis et al., 2015;Torlak \& Kuzey, 2019; Yuen et al., 2018).

In addition, as revealed in the results of this research the payment system dimension of job satisfaction has a significant impact on the performance of employees in the first place, followed by leadership style and organizational climate are second and third impact dimensions of job satisfaction on employees' performance. The results also showed that there is a positive and significant relationship between job satisfaction and employee performance. And high job satisfaction will lead to better performance. People like the payment system and promotion policy to be fair, unambiguous and in line with their expectations.

Depending on the type of job and the skill level of the individual, the amount of pay that is paid in any organization will create job satisfaction, if it is fair and will consequently improve performance. On the other hand, not everybody wants to make money in any way, because many people are conscious and willing to make less money, but want to work where they like and there is less discrimination. The nature of work, like pay, plays a large part in determining employee satisfaction in the job, in other words, work plays an important role in determining the level of job satisfaction. Generally, people want a job where there is competition, not just one continuous job without the slightest change. The most important mutually of the work that affects job satisfaction are;A- Diversity;B- Review of working practices and guidelines.

Generally, jobs that are moderately varied will increase job satisfaction. Probably the most fundamental trait in the concept of the nature of work is that work must be interesting and meaningful to individuals. Undoubtedly, this feature of job satisfaction is subject to a wide range of individual differences. Therefore, for people who differ in values, abilities, it is possible to find a specific type of job that is personally interesting, while repetitive and continuous work seems meaningless to them. It also improves one's morale because opportunities for development show the value of the individual to the organization, especially at higher levels. Promotional opportunities have a positive effect on job satisfaction and employee performance, as well as the promotion of high levels of the organization leads to positive change in self-esteem, coworkers' content and pay, so employees are always welcome to get promotions.

On the other hand, organizational culture and climate are important factors that influence job satisfaction, and most experts believe that organizational culture has a strong influence on the behavior and mental states of employees and in fact the key component of success in organizations and improvement of human resources. Whenever there is a great conflict between the values and standards of employees and organizational culture, there are problems and conflicts in the process of adapting to organizational culture that reduce job satisfaction and thus reduce organizational productivity. Leadership style is an important source of job satisfaction. Supervisors who have a friendly and supportive relationship with their subordinates, in which they develop a personal interest in themselves and provide greater satisfaction to employees. 
Another dimension is employee participation in decision making; managers who can provide employees with job satisfaction, fulfill the following two aspects: they have strong personal relationships with their employees and enable them to participate in decision making. Physical conditions in the workplace usually lead to job satisfaction if it is comfortable and risk-free. Moderate levels of temperature, humidity, ventilation, light and sound are very effective in creating material working conditions. Paying attention to the quality of work-life can lead to efficiency and job satisfaction. The design of proper light and low ambient noise have a major impact on one's mental state and performance. A job that is not rationally designed, that requires excessive movements, and unnecessarily moving employees to tools, equipment, and materials, leads to unhappiness and fatigue, and ultimately negative impact on employee efficiency and safety. Noise can also affect the focusing power of the person at the scene of the accident at work. Designing the workplace using colors and individual tastes can make it attractive.

\section{BASED ON THE RESULTS, THE FOLLOWING SUGGESTIONS ARE OFFERED}

The performance evaluation system is optimally implemented and use the results to pay for it, high-performing and high-scoring employees are given points and incorporated into the payment system.

Improvement of career development through the promotion of meritocracy, creating equal and competitive opportunities for employees to improve their capabilities, skills and interests, and to plan and manage the career path in the organization, utilizing the system. Proper performance appraisal as a basis for career promotion can lead to employee satisfaction and thus better job performance.

In the organization, employees need to feel that they are doing useful and productive work to achieve the necessary and sufficient satisfaction and interest. They should be aware of the importance of their work and should always have the opportunity to showcase their talents and abilities. Gaining the necessary knowledge about the various aspects of the work helps them to control their own people and to get closer to the desired level.

It is recommended that in each organization and company the characteristics and behavioral style of the supervisors, the ethical characteristics of the employees and the importance of the behavior between them be examined and continuous efforts are made to improve it. In addition, in some cases, managers pay more attention to bottom-up decision making and employee involvement in the decision-making process.

Finally, in order to optimize the working conditions, consult the employees and use their suggestions. As well as facilities and equipment necessary to carry out the activities to be provided and placed in the hands of employees.

\section{ACKNOWLEDGEMENT:}

We would like to express our sincere gratitude and appreciation to Al Hayat Company PEPSI in Erbil, and especially thanks to Miss. Dilbar Showan - Human Resources Manager, to her cooperation in collecting data from employees of this company as participants of the research 


\section{REFERENCES}

Abuhashesh, M., Al-Dmour, R. \& Masa'deh, R.E. (2019). Factors that affect Employees Job Satisfaction and Performance to Increase Customers' Satisfactions. Journal of Human Resources Management Research, Vol. 2019, 1-23.

Amburgey, W. O. D. (2005). An analysis of the relationship between job satisfaction, organizational culture, and perceived leadership characteristics, 8(1) University Central Florida.

Arifin, H. M. (2015). The Influence of Competence, Motivation, and Organisational Culture to High School Teacher Job Satisfaction and Performance. International Education Studies, (1), 38-45.

Bakotić, D. (2016). Relationship between job satisfaction and organisational performance. Economic research-Ekonomskaistraživanja, 29(1), 118-130.

Braun, S., Peus, C., Weisweiler, S., \& Frey, D. (2013). Transformational leadership, job satisfaction, and team performance: A multilevel mediation model of trust. The Leadership Quarterly,24(1), 270-283.

Chan, K. C., Gee, M. V., \& Steiner, T. L. (2000). Employee happiness and corporate financial performance. Financial Practice and Education, 10, 47-52.

Cronley, C., \& Kim, Y. K. (2017). Intentions to turnover: Testing the moderated effects of organizational culture, as mediated by job satisfaction, within the Salvation Army. Leadership \& Organization Development Journal, 38(2), 194-209.

Dahkoul, Z. M. (2018).Determinants of Employee Performance in Jordanian Organizations. Journal of Economics, Finance and Accounting (JEFA), 5(1), 11-17

Daily, C.M. \&Near, J.P. (2000). CEO satisfaction and firm performance in family firms: Divergence between theory and practice. Social indicators research, 51(2), 125-170.

Dugguh, S. I., \& Dennis, A. (2014). Job satisfaction theories: Traceability to employee performance in organizations. IOSR journal of business and management, 16(5), $11-18$.

Ellinger, A. D., Ellinger, A. E., Yang, B., \& Howton, S. W. (2002). The relationship between the learning organization concept and firms' financial performance: An empirical assessment. Human resource development quarterly, 13(1), 5-22.

Fu, W., \& Deshpande, S. P. (2014). The impact of caring climate, job satisfaction, and organizational commitment on job performance of employees in a China's insurance company. Journal of Business Ethics, 124(2), 339-349.

Gupta, K., \& Garg, I. (2017). Investigation of job satisfaction among employees: A case of hospitality industry in Ambala (India). Voice of Research, 6(1), 50-56.

Hee, O. C., Ong, S. H., Ping, L. L., Kowang, T. O., \& Fei, G. C. (2019). Factors Influencing Job Satisfaction in the Higher Learning Institutions in Malaysia. International Journal of Academic Research in Business and Social Sciences, 9(2), 10-20.

Huselid, M. A. (1995). The impact of human resource management practices on turnover, productivity, and corporate financial performance. Academy of management journal, $38(3), 635-672$.

Kampkötter, P. (2017). Performance appraisals and job satisfaction. The International Journal of Human Resource Management, 28(5), 750-774.

Khalaf, R. K. A., Hmoud, H. Y., \& Obeidat, B. (2019). Reviewing the Mediating Role of Job Satisfaction on the Effect of Employee Engagement on Organizational Performance. Journal of Social Sciences (COES\&RJ-JSS), 8(1), 7-23.

Koys, D. J. (2001). The effects of employee satisfaction, organizational citizenship behavior, and turnover on organizational effectiveness: A unit-level, longitudinal study. Personnel psychology, 54(1), 101-114. 
Latif, M. S., Ahmad, M., Qasim, M., Mushtaq, M., Ferdoos, A., \& Naeem, H. (2013). Impact of employee's job satisfaction on organizational performance. European Journal of Business and Management, 5(5), 166-171.

Lin, S., Lamond, D., Yang, C. L., \& Hwang, M. (2014). Personality traits and simultaneous reciprocal influences between job performance and job satisfaction. Chinese Management Studies, 8(1), 6-26.

Miha, M. (2018). The impact of employee job satisfaction toward organizational performance: A study of private sector employees in Kuching, East Malaysia.International Journal of Scientific and Research Publications, 8(12), 270278.

Mohr, A. T., \& Puck, J. F. (2007). Role conflict, general manager job satisfaction and stress and the performance of IJVs. European Management Journal, 25(1), 25-35.

Mueller, C. W., \& Kim, S. W. (2008). The contented female worker: Still a paradox? In Justice, 117-149. Emerald Group Publishing Limited.

Platis, C., Reklitis, P., \&Zimeras, S. (2015). Relation between job satisfaction and job performance in healthcare services. Procedia-Social and Behavioral Sciences, 175, 480-487.

Prange, C., \&Pinho, J. C. (2017). How personal and organizational drivers impact on SME international performance: The mediating role of organizational innovation. International Business Review, 26(6), 1114-1123.

Sari, N. P. R., Bendesa, I. K. G., \& Antara, M. (2019). The Influence of Quality of Work Life on Employees' Performance with Job Satisfaction and Work Motivation as Intervening Variables in Star-Rated Hotels in Ubud Tourism Area of Bali. Journal of Tourism and Hospitality Management, 7(1), 74-83.

Shields, J., Brown, M., Kaine, S., Dolle-Samuel, C., North-Samardzic, A., McLean, P., Johns, R., O'Leary, P., Robinson, J. \& Plimmer, G. (2015). Managing employee performance \& reward: Concepts, practices, strategies. Cambridge University Press.

Shooshtarian, Z., Ameli, F., \& AminiLari, M. (2013). The effect of labor's emotional intelligence on their job satisfaction, job performance and commitment. Iranian Journal of Management Studies, 6(1), 27-43.

Singhai, M. (2016). International science community association. Mini Review Paper., ResearchJournalofManagement,5(9), 66-68.

Torlak, N. G., \& Kuzey, C. (2019). Leadership, job satisfaction and performance links in private education institutes of Pakistan. International Journal of Productivity and Performance Management, 68(2), 276-295.

Yuen, K. F., Loh, H. S., Zhou, Q., \& Wong, Y. D. (2018). Determinants of job satisfaction and performance of seafarers. Transportation research part A: policy and practice, $110,1-12$. 